\title{
Gas Turbine Engine Control Design Using Fuzzy Logic and Neural Networks
}

\author{
M. Bazazzadeh, H. Badihi, and A. Shahriari \\ Department of Mechanical \& Aerospace Engineering, Malek-Ashtar University of Technology, Shahin Shahr, Isfahan, \\ Isf, 83145/115, Iran \\ Correspondence should be addressed to A. Shahriari, al.shahriari@gmail.com
}

Received 8 November 2010; Revised 11 March 2011; Accepted 6 June 2011

Academic Editor: Rick Lind

Copyright ( $\odot 2011$ M. Bazazzadeh et al. This is an open access article distributed under the Creative Commons Attribution License, which permits unrestricted use, distribution, and reproduction in any medium, provided the original work is properly cited.

This paper presents a successful approach in designing a Fuzzy Logic Controller (FLC) for a specific Jet Engine. At first, a suitable mathematical model for the jet engine is presented by the aid of SIMULINK. Then by applying different reasonable fuel flow functions via the engine model, some important engine-transient operation parameters (such as thrust, compressor surge margin, turbine inlet temperature, etc.) are obtained. These parameters provide a precious database, which train a neural network. At the second step, by designing and training a feedforward multilayer perceptron neural network according to this available database; a number of different reasonable fuel flow functions for various engine acceleration operations are determined. These functions are used to define the desired fuzzy fuel functions. Indeed, the neural networks are used as an effective method to define the optimum fuzzy fuel functions. At the next step, we propose a FLC by using the engine simulation model and the neural network results. The proposed control scheme is proved by computer simulation using the designed engine model. The simulation results of engine model with FLC illustrate that the proposed controller achieves the desired performance and stability.

\section{Introduction}

Gas turbine engines are constituted of a complex system. Their desired performance can guarantee the aircraft flight safety. This performance is impressed by some engine input controlling functions which are changing with the development of engines. Finding these functions can be a great success in jet engine control issue $[1,2]$. For example, when an airplane loses one of its operative engines during take off, the remaining engines should achieve their maximum thrust as fast as possible without any spools over speed, turbine inlet over temperature, and compressor surge. On the other hand, at a complex maneuvering by a fighter airplane, the engines should deliver more accurate thrust functions. Both of these examples can indicate the importance of the engine control issue.

While the traditional control techniques for aero-engines are time-tested and reliable, modern control techniques promise to provide improved control and therefore improved aircraft propulsion system performance $[3,4]$.
During the last five decades, most of control problems have been formulated by the objective knowledge of the given systems (e.g., mathematical model). Many of these "modelbase" approaches have found their way into practice and provided satisfactory solutions to the spectrum of complex systems [5].

However, there are many knowledge-based systems that cannot be merely described by the traditional mathematical representations $[6,7]$.

The knowledge-based approaches are much closer to human thinking than traditional classical approaches $[6,8]$.

In a broad perspective, knowledge-based approaches underlie what is called "soft computing". These methods include fuzzy logic (FL), neural networks (NN), genetic algorithms (GA), and probabilistic reasoning (PR). In addition, these methodologies in most part are complimentary rather than competitive [9].

Fuzzy logic has been the area of heated debate and much controversy during the last decades. The first paper in fuzzy set theory, which is now considered to be the 
seminar paper of the subject, was written by Zadeh (See [10]), who is considered the founding father of the field. In that work, Zadeh was implicitly advancing the concept of approximate human reasoning to make effective decisions on the basis of the available imprecise, linguistic information. The first implementation of Zadeh's idea was accomplished by Mamdani (see [11]) which demonstrated the ability of Fuzzy Logic Controller (FLC) for a small model steam engine. After this pioneer work, many consumer products and industrial applications using fuzzy technology have been developed and are currently available in whole of the world.

Fuzzy logic is one of the most effective approaches for intelligent control of complex nonlinear systems like aero-engines [4]. One of the important advantages of this approach is the simplicity of utilization. The other one is feasibility of increasing the number and type of membership functions and rules while it has wide variety of rules definition.

The engines of today are reliable and safe, but they are expensive to operate and maintain. With the integration of available models and algorithms for on-board operation and the resultant increase in on-board intelligence, engines of the future will be able to operate even more safely and reliably with reduced life cycle cost $[3,4]$.

With a renewed emphasis on reducing engine life cycle costs, improving fuel efficiency, increasing durability and life, and so forth, driven by various development programs, there is a strong push to do research on application of intelligent technologies for the engines.

The intelligent controlling approaches will provide the required scope for aero-engines to be more efficient, safe, and economic. These approaches offer the potential for creating extremely safe, highly reliable systems. The approaches will help to enable a level of performance that far exceeds that of today's propulsion systems in terms of reduction of harmful emissions, maximization of fuel efficiency, and minimization of noise, while improving system affordability and safety.

During the last decade, some research works have been carried out for intelligent control of gas turbine engines using fuzzy logic. In [12], the authors studied a combination of two potential techniques; fuzzy logic and evolutionary algorithms for a specific gas turbine. The controlling parameters include Inlet Guide Vane (IGV) angle and nozzle area. Similar work which has been presented in [13] is designing and evaluating two types of FLCs by controlling the combustor pressure. However, in the foresaid works and other related studies (see $[14,15]$ ), on the one hand, a comprehensive FLC has not been proposed that takes the flame-out and the safety limitations into account. Or on the other hand, the effect of fuel flow rate is not considered as a remarkable controlling parameter.

Generally, designing an appropriate controller for each specific aero-engine includes two steps: first, an accurate aero-engine model to simulate the engine behavior individually and second, system recognition. The system recognition as the most important step in creating suitable membership functions and rules is the knowledge of engine performance parameters and specially their relation during engine operation. One of the most important performance parameters is the fuel flow rate and its relation with turbine inlet temperature and compressor surge margin during various engine acceleration maneuverings.

In this paper, after designing an accurate simulator model for the engine, we consider the fuel flow rate directly as the most comprehensive controlling parameter which has significant effects on all engine performance parameters. A successful approach for achieving the system recognition is also presented. The proposed approach includes designing and training a neural network which simulate the engine performance backwardly. So it empowered us to obtain a series of fuel flow functions for various engine acceleration maneuverings. These functions were used in the process of membership functions definition.

\section{Turbine Engine Simulator Model (TESM)}

Engine performance characteristics at design point are important parameters obtained from engine design process. For initial definition work, the operating condition where an engine will spend most time has been traditionally chosen as the engine design point. Alternatively some important high power condition may be chosen. Either way, at the design point the engine configuration, component design and cycle parameters are optimised. A change to the engine design requires a different engine geometry, at a fixed operating condition [16].

The objective here is not to design an engine. Hence, there is a specific engine with fixed geometry and known parameters. We only seek to simulate different operating conditions of the engine including steady and transient operations.

There are several ways to do engine modeling and simulation such as traditional approaches, FORTRAN, or other 4th generation languages to calculate thermodynamics cycle parameters associated with the design and performance prediction of gas turbine engines. These cycle decks have been used extensively by developers of gas turbine engines to understand the behavior of jet engine designs prior to, during, and after the development of the physical engines. In addition to them, Simulink software and associated tools can be applied in the development of detailed, physics-based, turbine engine models.

Simulink provides an easy-to-use, graphical, modeling and simulation development environment for developing time-based simulations in a wide range of applications, and Simulink is capable of code generation using associated tools [17-19]. So, a dynamic model for a specific turbojet engine is developed using the MATLAB simulation environment and its Simulink toolbox [1]. The schematic configuration of the simulated turbojet engine is shown in Figure 1.

The engine model is constructed with a component approach for ease of modification and replacement with different engine components. The precision of Turbine Engine Simulator Model (TESM) results depends on the precision of each component module result [1].

Each component can be instantiated from a software library module developed to represent the functions of that 


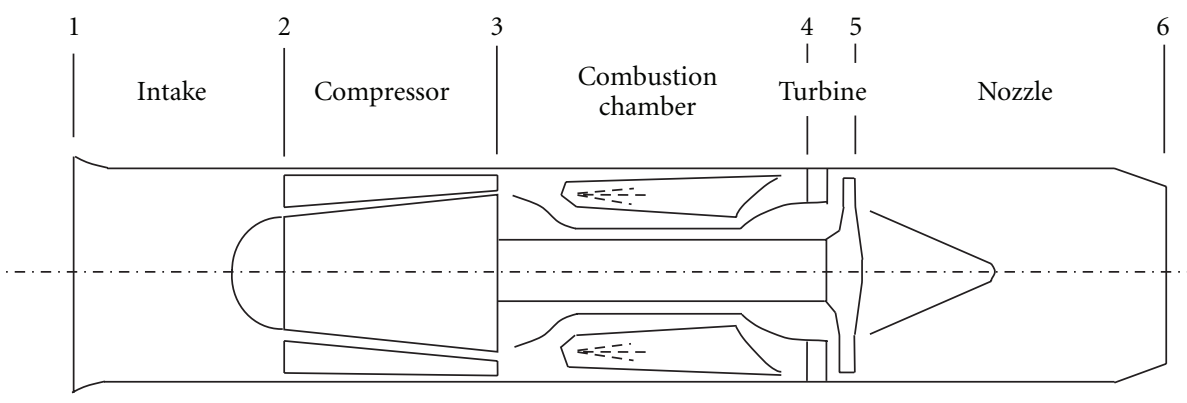

FIGURE 1: Schematic configuration of the simulated turbojet engine.

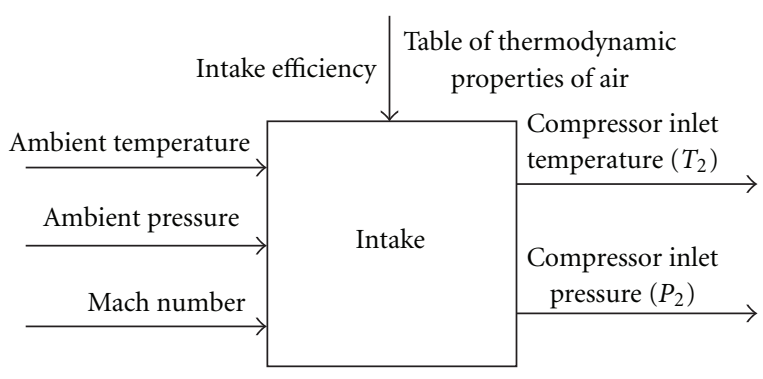

FIGURE 2: Intake module.

particular type of component. Each module is a functional unit with its own set of inputs and outputs (I/O). Each can function as an independent component. For example, the intake (Diffuser) module can be used as a stand-alone intake component, and it can be used to instantiate intake in the engine model. The intake module and its $\mathrm{I} / \mathrm{O}$ are shown in Figure 2.

TESM includes some component modules such as: Intake, Compressor, Combustor, Turbine, and Nozzle which are modeled as lumped parameter thermodynamic systems. It means that a multiple stage compressor or turbine is simulated as one component. This approach is adopted because compressor and turbine maps are created to represent the performance of the overall component. The model can be developed to a stage-by-stage fashion if we have required authentic performance data of each component.

The modules are developed based on fundamental laws of physics such as conservation of mass, momentum, and energy. For example, the rotor dynamics is presented by the equation of conservation of angular momentum, that is based on moment of inertia of the components attached to the shaft [16].

$$
\dot{N}=\frac{3600}{4 \pi^{2} N I}\left[W_{4} C_{P 4}\left(T_{4}-T_{5}\right)-\frac{W_{3} C_{P 3}\left(T_{3}-T_{2}\right)}{\eta_{\text {mech }}}\right],
$$

where $N$ is engine spool speed, $T$ is temperature, $W$ is mass flow, $I$ is engine spool moment of inertia, and $\eta_{\text {mech }}$ is the engine spool mechanical efficiency.
Other most important dynamical differential equations are used in the modeling process are as follows [16]:

$$
\begin{gathered}
\dot{\rho}=\frac{W_{3}-W_{4}+u}{C_{\mathrm{vol}}}, \\
\dot{T}_{4}=\frac{C_{P 3} T_{3} W_{3}-C_{P 4} T_{4} W_{4}+u \mathrm{LHV}}{C_{\mathrm{vol}} \dot{\rho}_{4} T_{4} C_{V}} .
\end{gathered}
$$

In order to use individual components to create an engine model, all hardware component information such as flow, pressure ratio and efficiency maps, flow volume, and area of some components is required.

The incorporation of turbo machinery map data (compressor and turbine maps) into the MATLAB workspace (Simulink-related blocks) is a significant part of the tuning process required to match the model performance with data for a specific engine.

The other parameters to be incorporated into the MATLAB workspace are characteristic lengths, volumes, moments of inertia, design constants, efficiencies, and so forth. Values for these tuning parameters must be determined from engine design documentation, experimentation, or other simulation models. The model references these parameters at run-time.

One of TESM outputs is compressor surge margin which is highly important for safe engine operation. Compressor surge is a condition affecting both aerospace and industrial compression systems that employ turbomachinery. Surge is an unstable operating condition that can lead to the loss of an aircraft in aerospace applications and cause severe damage to industrial systems. During this compression system instability, the flow over the blades of the compressor stalls, and the pressure rise capability is reduced. When this occurs, the compressor cannot maintain the high-pressure downstream and a violent flow reversal occurs throughout the compression system.

Surge Margin (SM) of compressor refers to a margin of safety between the normal operating point of the compressor and the stability limit. Surge Margin is obtained using the incorporated turbo machinery map data, as follows [1]:

$$
\mathrm{SM}=\left(\frac{\left(P_{32} / \dot{m}_{2 a_{\mathrm{cor}}}\right)_{\text {stall }}-\left(P_{32} / \dot{m}_{2 a_{\mathrm{cor}}}\right)}{\left(P_{32} / \dot{m}_{2 a_{\mathrm{cor}}}\right)}\right), \quad P_{32}=\left(\frac{P_{3}}{P_{2}}\right) .
$$

The model configuration is shown in Figure 3. As can be seen, the relationships between components are easily 


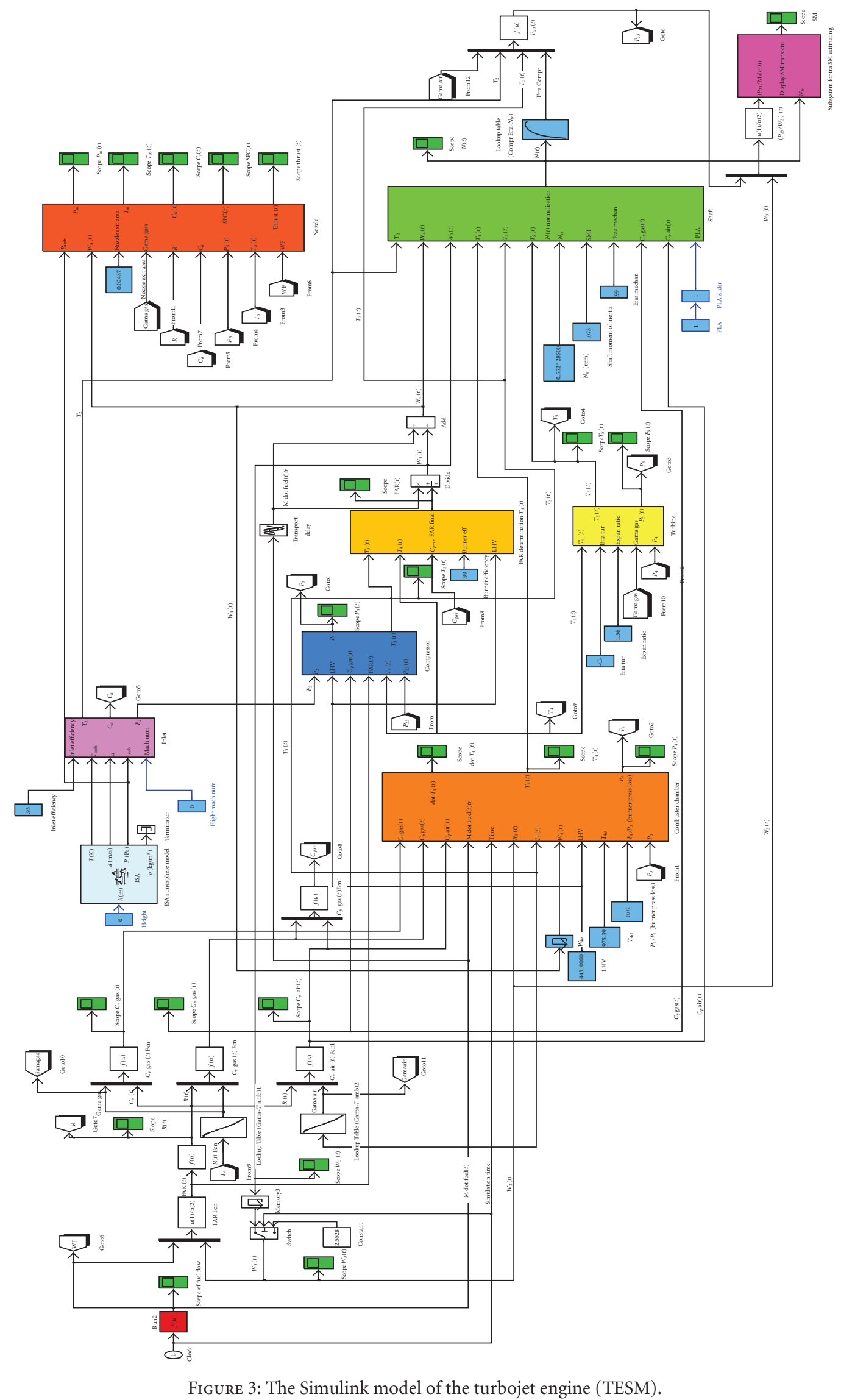


TABLE 1: Turbine engine simulator model outputs.

\begin{tabular}{lc}
\hline Component module & Output parameters \\
\hline ISA.Atms.Model & $a, \rho, P_{1}, T_{1}$ \\
Intake & $P_{2}, T_{2}$ \\
Compressor & $P_{3}, T_{3}, W_{3}$ \\
Combustor & $P_{4}, T_{4}, W_{4}$ \\
Turbine & $P_{5}, T_{5}$ \\
Nozzle & Thrust, $\mathrm{SFC}, P_{56}, T_{56}, C_{6}$ \\
Shaft & $\mathrm{N}$ \\
Surge margin model & $\mathrm{SM}$ \\
\hline
\end{tabular}

understood and the gas path flow parameter connections between major engine components include mass flow rate, total temperature and pressure, static pressure, and Fuel-Air Ratio (FAR).

This model provides a basic framework for both the development of engine component modules and analysis of component interactions at the system level within the engine. Component modules can be reused and the time and cost required to produce new models significantly reduced.

TESM has three main inputs including altitude and Mach number, which are ambient inputs (Flight Data), and fuel flow to the combustor chamber. The inputs are detailed below.

(a) Altitude: this is an ambient input with a range of 10,000 feet for this type of engine which goes into the ISA atmosphere model block.

(b) Mach number: this simulates the speed of aircraft and its effects on $P_{2}, T_{2}$, and $C_{a}$. The range for this type of engine Mach number is 0 to 0.9 .

(c) Fuel flow: this is an important input from an engine control point of view and is set by a controller for a specific demanded Power Lever Angle (PLA).

The engine transient operation can be indicated by TESM's outputs. Table 1 presents some of these outputs.

Among the model outputs, four are the most important, including: engine spool speed $(N)$, turbine inlet temperature $\left(T_{4}\right)$, compressor surge margin $(\mathrm{SM})$, and engine thrust. These should be controlled by engine controllers. Figure 4 presents TESM and its more important inputs and outputs.

The model operates as a virtual test cell and enables a user to investigate "what-if" scenarios at a fraction of the cost of an engine test cell or research aircraft.

Now, to present an efficient method to estimate the fuel flow injection function to the combustor chamber which is of great importance among the engine input controlling functions (See $[1,2,20,21]$ ), some different reasonable fuel flow functions are applied via the engine model, and then some important engine continuous time operation parameters (such as thrust, compressor surge margin, turbine inlet temperature, and engine spool speed, etc.) are obtained. These parameters and the fuel flow functions provide a precious database which can be used by a neural network.

Each of the foresaid fuel flow functions as an important part of the database is a series of two-dimensional vectors.
Since the engine accelerates from normalized spool speed of $n=0.55$ to $n=1.1$, the starting and ending points of the functions concern the related steady state values of fuel flow. As a general rule, the Fuel-Air Ratio (FAR) put some constraints on variation of fuel flow rate. In this regard, the derivative of a fuel flow function should be restricted by some prespecified values for the engine. By considering all of the foresaid constraints and the compressor map, a series of discrete points would be obtained. These points are used to estimate the fuel flow functions.

\section{Neural Network Training}

Neural networks are a powerful technique to solve many real-world problems. They have the ability to learn from experience in order to improve their performance and to adapt themselves to changes in the environment. In addition to that, they are able to deal with incomplete information or noisy data and can be very effective especially in situations where it is not possible to define the rules or steps that lead to the solution of a problem [2].

By designing and training a feedforward multilayer perceptron neural network according to the available database; we estimate a number of different reasonable fuel flow functions providing the desired engine performance parameters such as thrust and compressor surge margin for various acceleration maneuverings. The selected engine maneuverings only include twelve fast and safe accelerations for pilot's full throttle commands to cover the critical range of engine operation. The different rates of full throttle commands will diversify these maneuverings. In fact, the proposed neural network simulates the engine performance backwardly. So a series of fuel flow functions would be obtained for various engine acceleration maneuverings. These functions will be used in the process of membership functions definition for designing a fuzzy logic controller.

The network input layer consists of four neurons which are the most important engine performance parameters and acquired by the engine model. These engine model output parameters are depicted in Figure 4. There are ten neurons in the hidden layer. The output layer includes one neuron as the fuel flow rate. The proposed neural network is shown in Figure 5.

We use back propagation algorithm as a reliable and well-known algorithm to train the network. Applying this algorithm would minimize output error by changing the synapse weights.

Three hundred training data and fifty testing data are used by the network. The network activity function is as follows:

$$
f(x)=\frac{1}{1+e^{-x}} .
$$

Since the above function provides normalized outputs between zero and one; so the inputs of the network should be normalized too. At last, the proposed network would achieve to acceptable error by 3500 epochs and training process finish. 


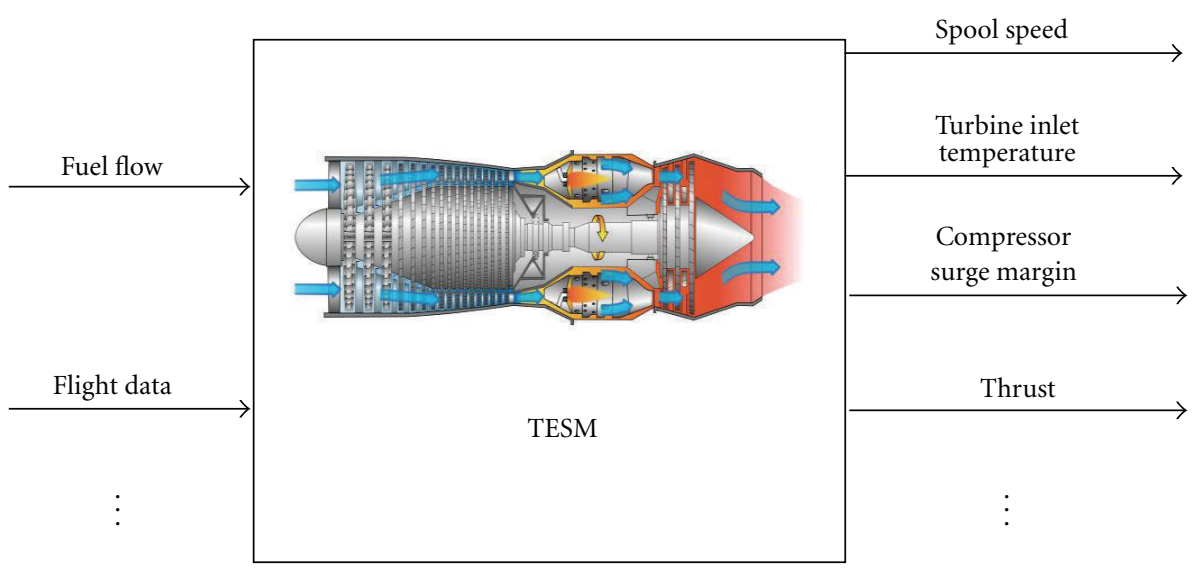

FIGURE 4: The turbine engine simulator model.

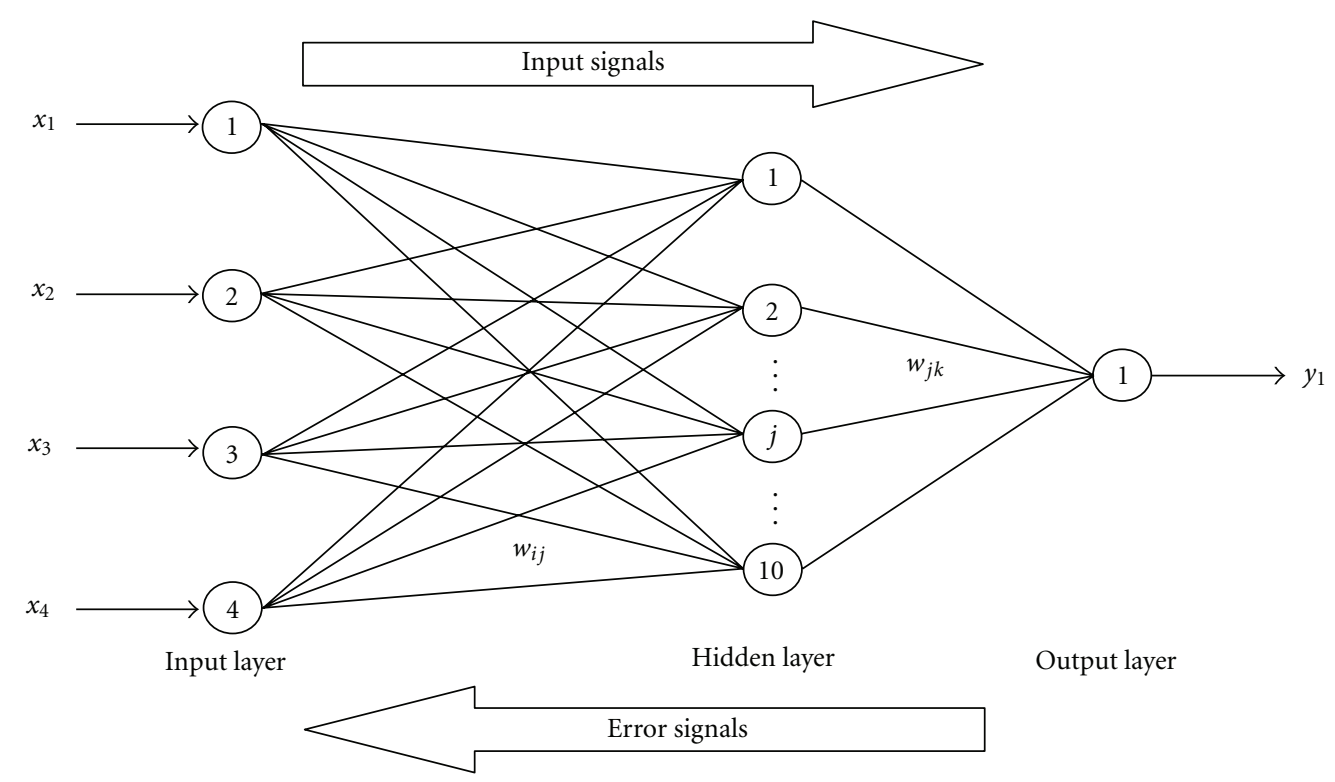

FIGURE 5: The three-layer back propagation neural network.

\section{Designing a Fuel Flow Controller by the Aid of Fuzzy Logic Method}

Fuzzy logic is an increasingly popular method of handling systems associated with uncertainty, unmodeled dynamics, or simply where human experience is required. Its ability to deal with imprecise data can often offer an immediate benefit over conventional mathematical reasoning. It has been widely employed in control problems, particularly due to its ability to mimic the behavior of nonlinear plants. By ensuring that a properly formulated rule base is found, a fuzzy system can provide smooth transitions between operating regimes $[12,22]$.

An FLC utilizes fuzzy logic to convert linguistic information based on expert knowledge into an automatic control strategy. In order to use the fuzzy logic for control purposes, a front-end "fuzzifier" and a rear-end "defuzzifier" are added to the usual input-output data set [11]. An FLC commonly consists of four sections: rules, fuzzifier, inference engine, and defuzzifier. Once the rule has been established, the controller can be considered as a nonlinear mapping from the input to the output. The block diagram (see Figure 6) of the generalized indistinct controller consists of four elements [23]:

(1) fuzzification block, transforming input physical values $y_{i}$ into corresponding linguistic variables $\mu\left(\mathrm{y}_{i}\right)$;

(2) fuzzy rule base, including:

(a) knowledge base, containing rules table for logic output block;

(b) logic output block, transforming input linguistic variables into output with some belonging functions;

(3) defuzzification block, transforming output linguistic variables into physical control influence. 


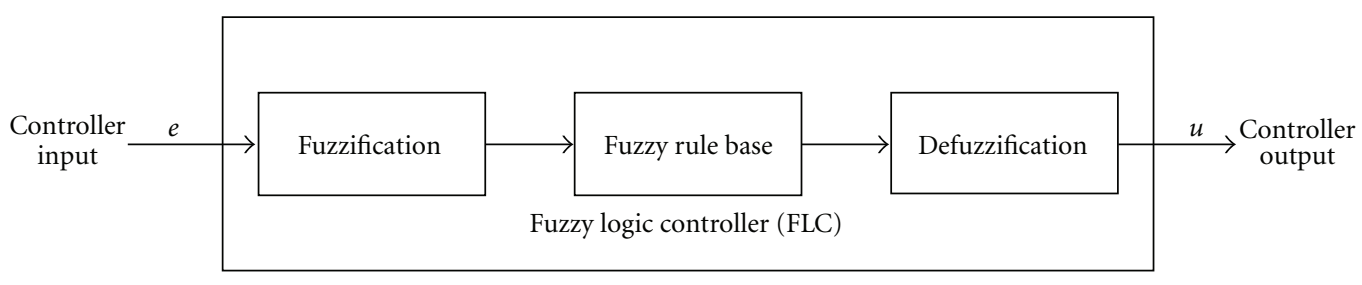

FIgURE 6: The block diagram of the generalized indistinct controller.

The first input of controller is the spool speed error (the difference of throttle demanded spool speed and current spool speed). This input is named Error. The defined fuzzy function for the input is shown in Figure 8. The second input is the first input variations over time. This input is named Delta Error. The defined fuzzy function for the second input is shown in Figure 9.

The designed FLC would determine the amount of fuel flow to the combustor chamber over its transient operation. The FLC and the available turbine engine model constitute a closed loop which is shown in Figure 7.

Defining the proper fuzzy membership functions for fuel flow has a great influence on the controller behavior. So, the obtained desired fuel flow functions as the neural network results would be helpful for defining the fuel flow fuzzy membership functions. This approach is helpful to defuzzify the fuzzy fuel flow membership functions.

In this regard, each of the obtained desired fuel flow functions is separately considered over fifteen equispaced time intervals in $[0.0,3.5]$. So an equal number of nonequispaced intervals are also obtained on each fuel flow axis. Since the rate of fuel flow injection is much higher over the starting time intervals (starting phase of acceleration), so a large number fuel flow intervals are situated close to the end part of their axis. Fuel flow intervals on a sample desired fuel flow function are depicted by different arrows in Figure 10.

Using a simple mapping method, each of these intervals creates a triangular fuel flow membership function. According to the proposed mapping, the membership degree for midpoint of an interval is one and for endpoints is zero. With respect to the proposed arrangement of intervals in Figure 10, the first three of fuel flow fuzzy membership functions are presented in Table 2.

A similar approach is applied for each desired fuel flow function. Then, the obtained fuzzy fuel flow functions are used to define a final set of fuel flow fuzzy membership functions. In this regard, for each fuel interval the Arithmetic mean of fuel values with the highest membership degree is obtained and labeled with maximum membership degree. These final membership functions are used in designing procedure of the FLC.

Conventionally, fuzzy rules are established by a combination of knowledge, experience, and observation and may thus not be optimal. Additionally, in spite of efforts to formalize a development standard for fuzzy controllers, fine tuning its performance is still a matter of trial and error $[5,12,22]$.

A variety of membership functions can be defined for inputs and output of the controller. By changing the number and types of the functions and rules, the engine behavior would change.

The acceleration time to achieve pilot demanded operation point is of great importance. This time should be short as much as possible [16]. On the other hand, if the acceleration time be shorter than its allowable limit, compressor surge would be likely. So, it is necessary for the FLC to limit the inordinate engine acceleration.

In this paper, the applied logic for creation the FLC rules includes higher spool acceleration rates during lower spool speeds and lower spool acceleration rates during higher spool speeds. Some selected rules which produce the central part of control surface are presented in Table 3.

The defuzzification process, which takes place after the generation of the fuzzy control signals, is completed using the inference mechanism. The resulting fuzzy set must be converted to a quantity which would be sent to the process regulating valve as a control signal. In this part, the inference results of all activated logic rules are synthesized into crisp output for making a decision. In this study, the logic AND has been implemented with the minimum operator, and the defuzzification method is based on bisector area.

The variation of fuel flow versus the two controller inputs is depicted in Figure 11.

By designing the controller, the influence of controller parameters on turbine engine should be examined in more detail. So it would be essential to simulate the turbine engine and controller simultaneously.

\section{Testing and Demonstration}

The turbine engine acceleration for full throttle command would be considered to achieve the most critical condition. The simulations are run with the unit step power lever angle and constant zero values for Mach number and altitude.

The desirable engine performance would be obtained by applying more and various types of membership functions and rules and then rerunning the simulation program. This technique is effective to achieve the best fuzzy logic controller. The simulation results of engine model with FLC are presented in Figure 12.

When the turbine output power overcomes the compressor input power, the acceleration operation will be done. So, increasing the fuel flow rate is a common method to accelerate the engine spool.

Through the initial time of acceleration, the turbine inlet temperature and the compressor output pressure will be risen and the compressor air flow rate reduced. Considering 


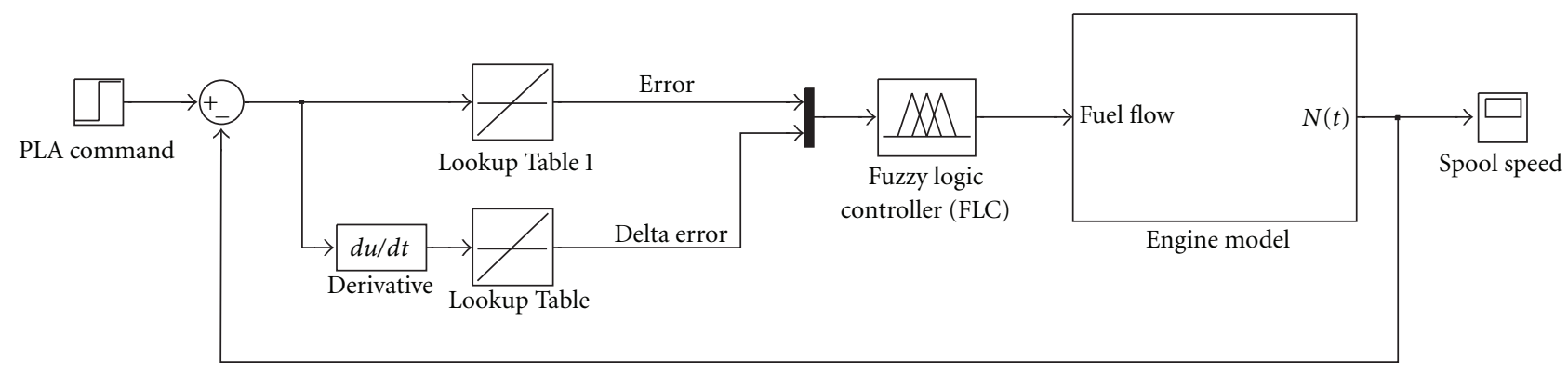

FIgURE 7: Layout of the turbojet engine simulator model and FLC.

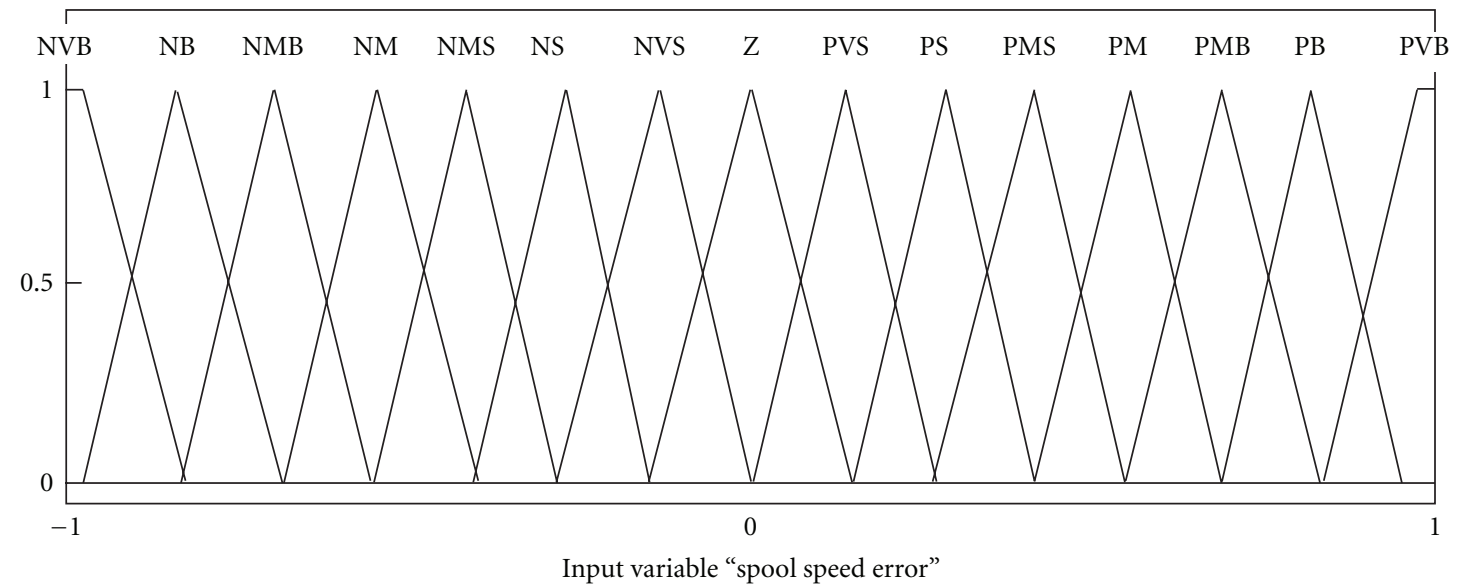

FIgURE 8: Error membership functions.

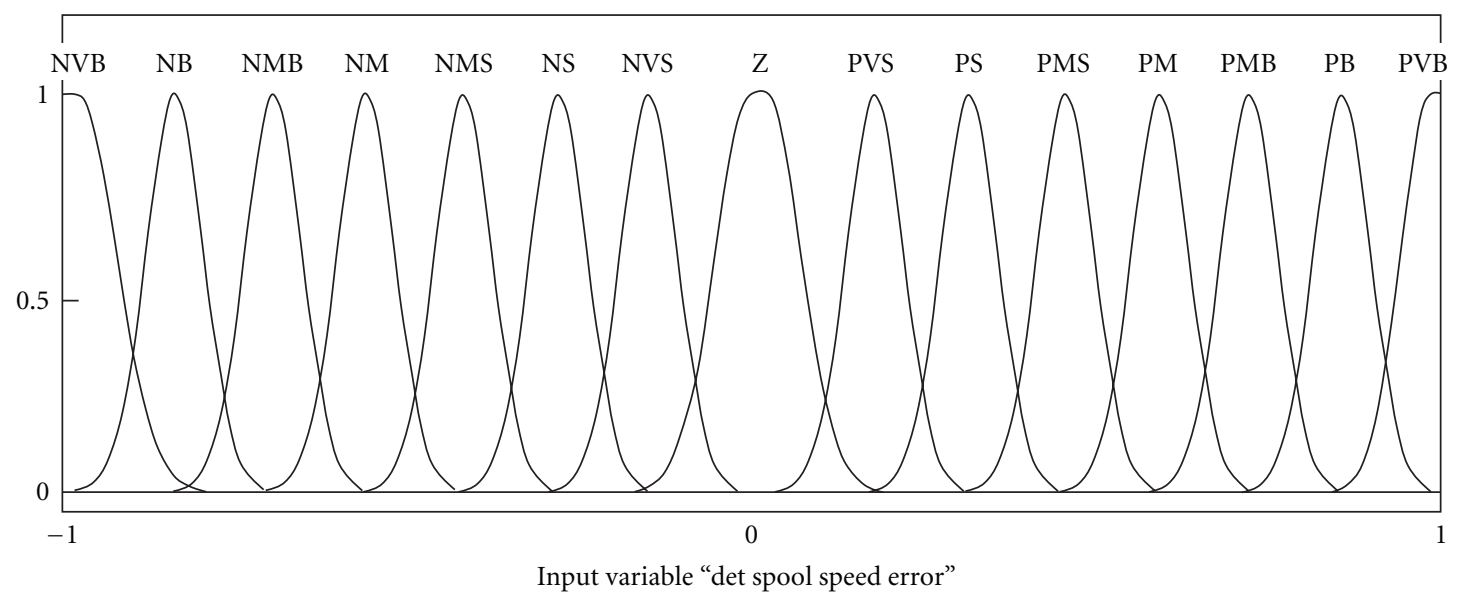

FIGURE 9: Delta error membership functions.

TABLE 2: The first three of fuel flow intervals and the related membership degrees.

\begin{tabular}{|c|c|c|c|c|c|c|c|c|c|}
\hline \multirow{2}{*}{$\begin{array}{l}\text { Function name } \\
\text { Fuel interval points }\end{array}$} & \multicolumn{3}{|c|}{ NVB } & \multicolumn{3}{|c|}{ NB } & \multicolumn{3}{|c|}{ NMB } \\
\hline & First & Central & End & First & Central & End & First & Central & End \\
\hline Fuel amounts & - & 0.036 & 0.041 & 0.036 & 0.042 & 0.047 & 0.042 & 0.051 & 0.062 \\
\hline Membership degree & - & 1.0 & 0.0 & 0.0 & 1.0 & 0.0 & 0.0 & 1.0 & 0.0 \\
\hline
\end{tabular}


TABLE 3: Selected fuzzy rules.

\begin{tabular}{llcccccc}
\hline Error & & & & Delta-Error & & \\
& NMS & NS & NVS & Z & PVS & PS & PMS \\
\hline NMS & NMS & NS & NS & NS & NS & NVS & Z \\
NS & NMS & NS & NS & NS & NVS & Z & PVS \\
NVS & NMS & NS & NS & NVS & Z & PVS & PS \\
Z & NMS & NS & NVS & Z & PVS & PS & PMS \\
PVS & NMS & NS & NVS & Z & PVS & PS & PMS \\
PS & NVS & Z & Z & Z & PVS & PS & PMS \\
PMS & Z & PVS & PS & PS & PS & PS & PMS \\
\hline
\end{tabular}

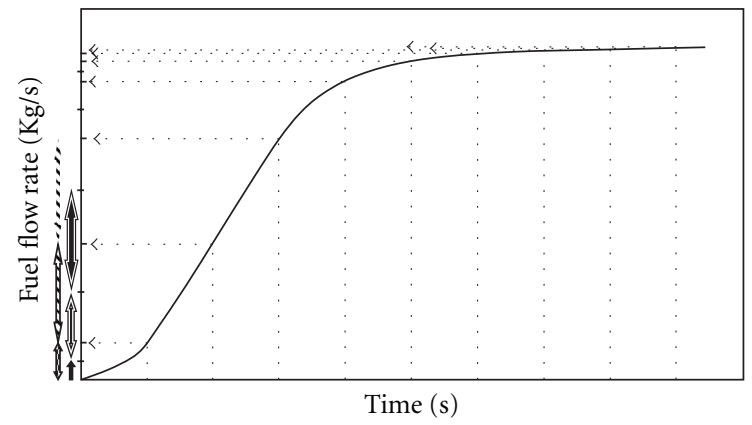

Figure 10: Fuel flow interval construction on a desired sample fuel flow function.

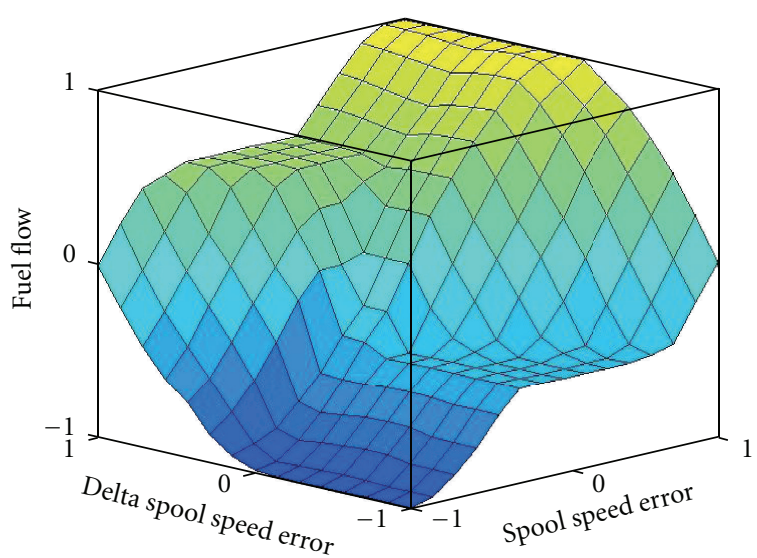

Figure 11: Control surface output of the Fuzzy Logic Controller (FLC).

the said circumstances during engine acceleration, high acceleration rate may lead to compressor surge or stall and excessive turbine inlet temperature which must be controlled by FLC. Figures 12(c) and 12(d) demonstrate the FLC capability in providing the above requirements.

The acceptability of gas turbine engine is crucially influenced by its ability in producing a demanded thrust while desirable fuel consumption. The demanded thrust for the jet engine is $3500(\mathrm{~N})$. Figure 12(b) shows the FLC capability in reaching the demanded thrust.
The simulation results of engine model with fuzzy controller in comparison with the engine model with a conventional controller are presented in Table 4 .

As it is seen from Table 4, the proposed FLC has led to more rapid acceleration and lower turbine inlet temperature. However, the SM is reduced in comparison with the conventional controller.

One of important inputs for FLC is the engine spool speed error which is shown in Figure 13. The magnitude of this error varies from its maximum (0.55) at the start of simulation to its minimum (zero) by achieving the demanded spool speed.

At the end of specified engine acceleration, some parameters such as time of engine acceleration and thrust are presented in Table 5. The acceleration time has reduced by FLC. This would be an important advantage of the proposed FLC.

Whether a fuzzy control design will be stable is a somewhat open question. The problems of FLC stability analysis and optimality are not addressed explicitly; such issues are still open problems in fuzzy controller design. Various nonlinear stability analysis methodologies could be applied for analyzing fuzzy control systems. Some methods have been proposed based on the Lyapunov's second method. The second method of Lyapunov (also referred to as the direct method) is the most general for determining the stability of a nonlinear and/or time-variant system of any order. It is a hot research topic now. In this project, the response curves of the system and its parameters including rise time, overshoot ratio, and settle time may be analyzed for specifying the performance of the FLC. The proper parameters for system response are obtained by adjusting either the rules, the input and output scaling factors, or some other parameters of the FLC. Using the foresaid method, the control loop behavior for the system presented in this paper is well known and considered sufficient.

\section{Conclusion}

The rationale behind this study was the need to develop a new technique that may be able to improve the performance, and simultaneously enhance the flexibility, of the control strategy for future concepts in aero-engines. These engines include nonconventional engines or multiregime engines which are used by modern military aircraft with more complex maneuvers. 


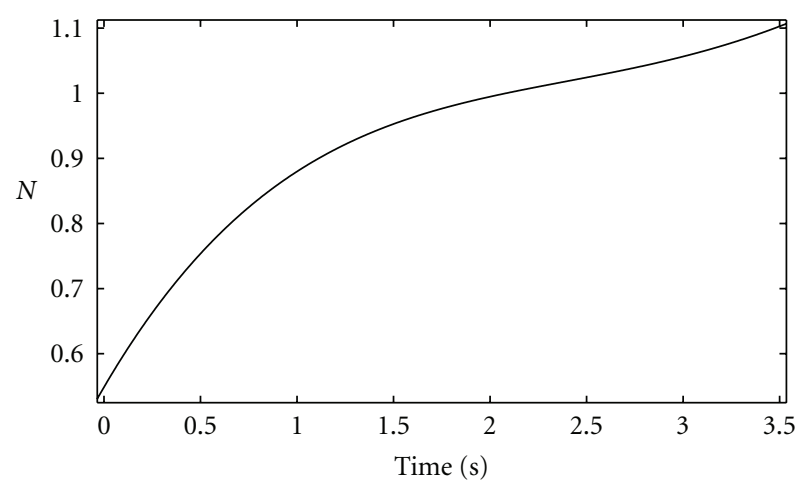

(a)

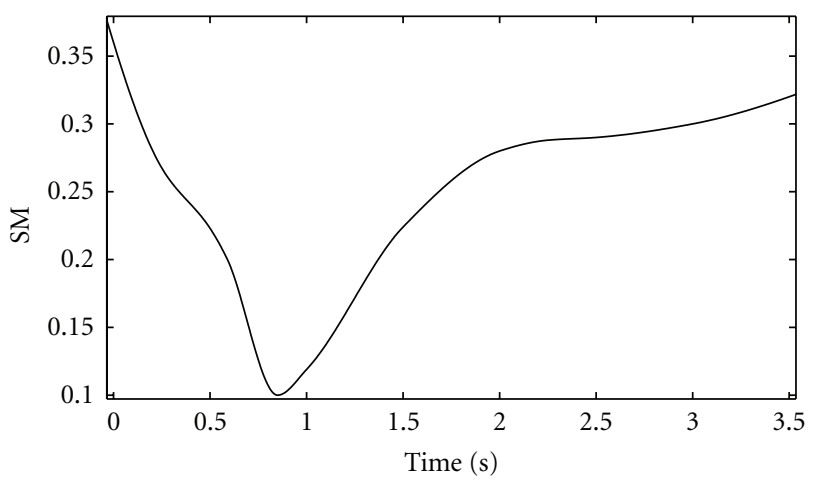

(c)

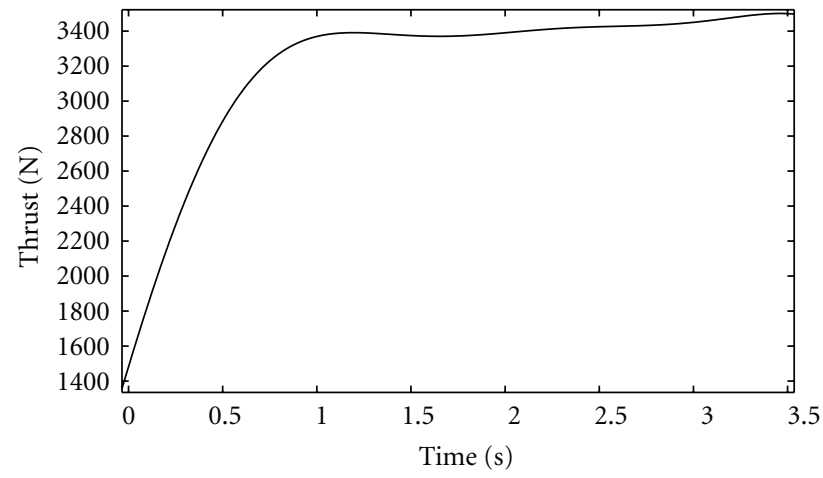

(b)

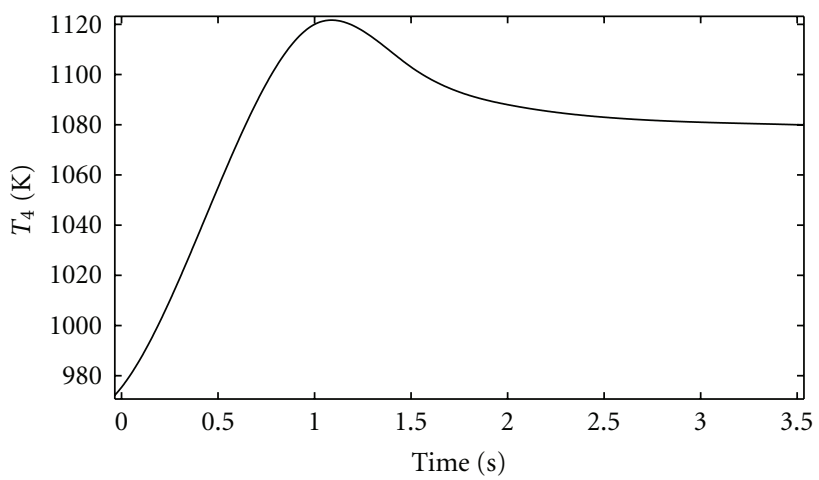

(d)

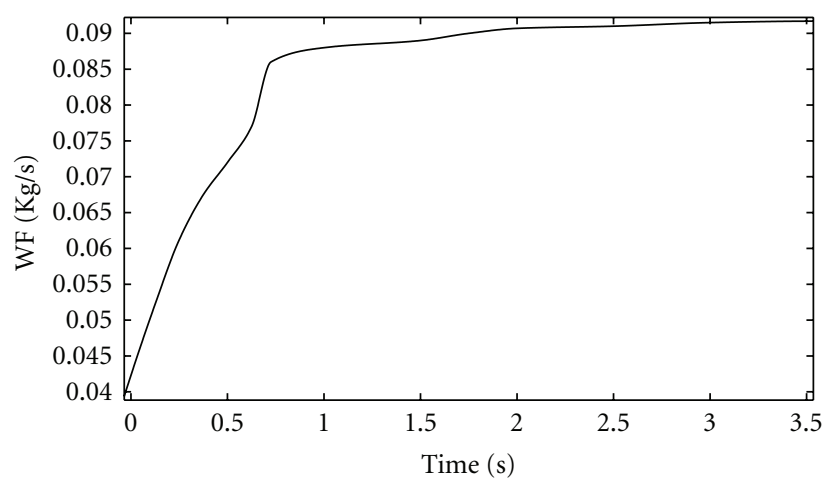

(e)

Figure 12: Trace of engine model responses with PLA Movement at sea level, $M=0$ versus simulation time (s). (a) Normalized rotational speed. (b) Thrust (N). (c) Surge margin. (d) Turbine inlet temperature (K). (e) Fuel flow.

TABLE 4: Simulation results of engine model with FLC in comparison with the engine model with conventional controller.

\begin{tabular}{|c|c|c|c|c|c|c|c|c|c|c|}
\hline \multirow{2}{*}{$\begin{array}{l}\text { Parameter } \\
\text { Time (Sec) }\end{array}$} & \multicolumn{5}{|c|}{ Fuzzy logic controller (simulation) } & \multicolumn{5}{|c|}{ Conventional controller (simulation) } \\
\hline & 0 & 0.8 & 1.6 & 2.4 & 3.2 & 0 & 0.8 & 1.6 & 2.4 & 3.2 \\
\hline $\begin{array}{l}\text { Spool speed } \\
\text { (normalized) }\end{array}$ & 0.55 & 0.86 & 0.96 & 1.02 & 1.05 & 0.55 & 0.74 & 0.84 & 0.95 & 0.98 \\
\hline $\begin{array}{l}\text { Turbine inlet } \\
\text { temperature } \\
(\mathrm{K})\end{array}$ & 975.39 & 1118 & 1098 & 1086 & 1081 & 975.39 & 1129 & 1119 & 1109 & 1103 \\
\hline Thrust (N) & 1482 & 3404 & 3462 & 3471 & 3478 & 1482 & 3379 & 3393 & 3409 & 3412 \\
\hline SM & 0.36 & 0.1 & 0.23 & 0.29 & 0.31 & 0.36 & 0.12 & 0.26 & 0.33 & 0.35 \\
\hline
\end{tabular}




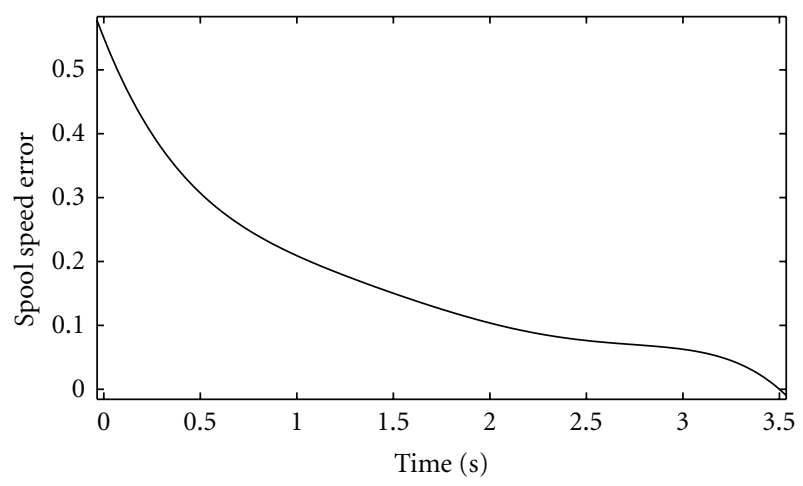

FIgURE 13: Trace of engine spool speed error.

TABLE 5: Simulation results of engine model with fuzzy controller in comparison with the engine testing operation.

\begin{tabular}{lcc}
\hline Parameter & $\begin{array}{c}\text { Fuzzy logic controller } \\
(\text { simulation }) \\
N=1.1\end{array}$ & $\begin{array}{c}\text { Conventional } \\
\text { controller (test) } \\
N=1.1\end{array}$ \\
\hline Time (Sec) & 3.5 & 4.2 \\
Thrust (N) & 3484 & 3420 \\
\hline
\end{tabular}

As engines become more complex and have more controllable and measurable parameters, the need for such technique will increase if they are to achieve their full potential.

The steady and transient simulations indicated the fuel flow importance as a comprehensive controlling parameter which has significant effects on all engine performance parameters. So the control system featured loops to prevent engine over speeds, compressor surge, and check turbine inlet temperature limit by scheduling the fuel flow during accelerations and decelerations. The spool speed error and its differential over time were used as fuzzy controller inputs. The influence of controller parameters on the turbine engine performance was analyzed by changing the number and types of the membership functions and rules. This is effective to design the best controller. The designed neural network simulated the engine performance backwardly. So it empowered us to obtain a series of fuel flow functions in various engine acceleration maneuverings. These functions were used in the process of membership functions definition.

The results obtained from full throttle simulation of the turbine engine and controller proved logical and well founded. The compressor surge margin is safe, and turbine inlet temperature is restricted by lower allowable value.

The simulation results of engine model with fuzzy controller illustrate that the proposed controller achieves the desired performance.

\section{Nomenclature}

A: Sound speed

$C_{p}$ : Specific heat

$C_{v}$ : Constant volume specific heat
$C_{\text {vol }}$ : Combustor volume

I: $\quad$ Polar moment of inertia

LHV: Fuel low heating value

M: $\quad$ Mach number

$\dot{m}_{a}$ : Air mass flow

$N$ : $\quad$ Engine spool speed

$P: \quad$ Pressure

SM: Compressor surge margin

T: $\quad$ Temperature

$u$ : Fuel mass flow $\left(\dot{m}_{f}(t)\right)$

$W: \quad$ Flow rate

$\eta_{\text {mech }}$ : Mechanical efficiency

$\alpha$ : $\quad$ Moment coefficient

$\rho: \quad$ Density

$x$ : Input value

$y: \quad$ Output value

w: Weight.

\section{References}

[1] M. Bazazzade, H. Badihi, and A. Shahriari, "Improved turbine engine hierarchical modeling and simulation based on engine fuel control system," Journal of Aerospace Science \& Technology, vol. 6, pp. 45-53, 2009.

[2] H. Badihi, A. Shahriari, and A. Naghsh, "Artificial neural network application to fuel flow function for demanded jet engine performance," in Proceedings of the IEEE Aerospace Conference, IEEE, Big Sky, Mont, USA, March 2009.

[3] L. C. Jaw and S. Garg, "Propulsion Control Technology Development in the United States (A Historical Perspective)," NASA, Glenn Research Center, Cleveland, Ohio, USA, 2005.

[4] J. S. Litt, D. L. Simon, S. Garg et al., "A Survey of Intelligent Control and Health Management Technologies for Aircraft Propulsion Systems," NASA, Glenn Research Center, Cleveland, Ohio, USA, 2005.

[5] P. J. Antsaklis and K. M. Passino, An Introduction to Intelligent and Autonomous Control, Kluwer Academic, Boston, Mass, USA, 1993.

[6] L. A. Zadeh, "A fuzzy-set-theoretical interpretation of linguistic hedges," Journal of Cybernetics, vol. 2, no. 3, pp. 4-34, 1972.

[7] M. M. Gupta, Advances in Fuzzy Set Theory and Application, North-Holland, Amsterdam, The Netherlands, 1987.

[8] B. Kosko, Neural Networks and Fuzzy Systems: A Dynamical Systems Approach to Machine Intelligence, Prentice Hall, New York, NY, USA, 1991.

[9] L. A. Zadeh, G. J. Klir, and B. Yuan, Fuzzy Sets, Fuzzy Logic, Fuzzy Systems: Selected Papers, World Scientific Publishing, River Edge, NJ, USA, 1996.

[10] L. A. Zadeh, "Fuzzy sets," Information and Control, vol. 8, no. 3, pp. 338-353, 1965.

[11] E. H. Mamdani and S. Assilian, "An experiment in linguistic synthesis with a fuzzy logic controller," International Journal of Man-Machine Studies, vol. 7, no. 1, pp. 1-13, 1975.

[12] A. J. Chipperfield, B. Bica, and P. J. Fleming, "Fuzzy scheduling control of a gas turbine aero-engine: a multiobjective approach," IEEE Transactions on Industrial Electronics, vol. 49, no. 3, pp. 536-548, 2002.

[13] A. Zilouchian, M. Juliano, T. Healy, and J. Davis, "Design of a fuzzy logic controller for a jet engine fuel system," Control Engineering Practice, vol. 8, no. 8, pp. 873-883, 2000. 
[14] J. W. Kim and S. W. Kim, "Design of incremental fuzzy PI controllers for a gas-turbine plant," IEEE/ASME Transactions on Mechatronics, vol. 8, no. 3, pp. 410-414, 2003.

[15] A. Martucci and A. J. Volponi, "Fuzzy fuel flow selection logic for a real time embedded full authority digital engine control," Journal of Engineering for Gas Turbines and Power, vol. 125, no. 4, pp. 909-916, 2003.

[16] P. P. Walsh and P. Fletcher, Gas Turbine Performance, Blackwell, Malden, Mass, USA, 2004.

[17] A. Behbahani, R. K. Yedavalli, P. Shankar, and M. Siddiqi, "Modeling, diagnostics and prognostics of A two-spool turbofan engine," in Proceedings of the 41st AIAA/ASME/SAE/ASEE Joint Propulsion Conference and Exhibit (AIAA '05), Tucson, Ariz, USA, July 2005.

[18] G. Crosa, F. Pittaluga, A. Trucco, F. Beltrami, A. Torelli, and F. Traverse, "Heavy-duty gas turbine plant aerothermodynamic simulation using simulink," Journal of Engineering for Gas Turbines and Power, vol. 120, no. 3, pp. 550-555, 1998.

[19] M. Lichtsinder and Y. Levy, "Jet engine model for control and real-time simulations," Journal of Engineering for Gas Turbines and Power, vol. 128, no. 4, pp. 745-753, 2006.

[20] K. Lietzau and A. Kreiner, "Model Based Control Concepts for Jet Engines," ASME Paper, 2001.

[21] K. Lietzau and A. Kreiner, "The Use of Onboard Real-Time Models for Jet Engine Control,” MTU Aero Engine Germany, 2004.

[22] G. M. Nelson and H. Lakany, "An investigation into the application of fuzzy logic control to industrial gas turbines," Journal of Engineering for Gas Turbines and Power, vol. 129, no. 4, pp. 1138-1142, 2007.

[23] L. Reznik, Fuzzy Controllers, NEWNES, Melbourne, Australia, 1997. 

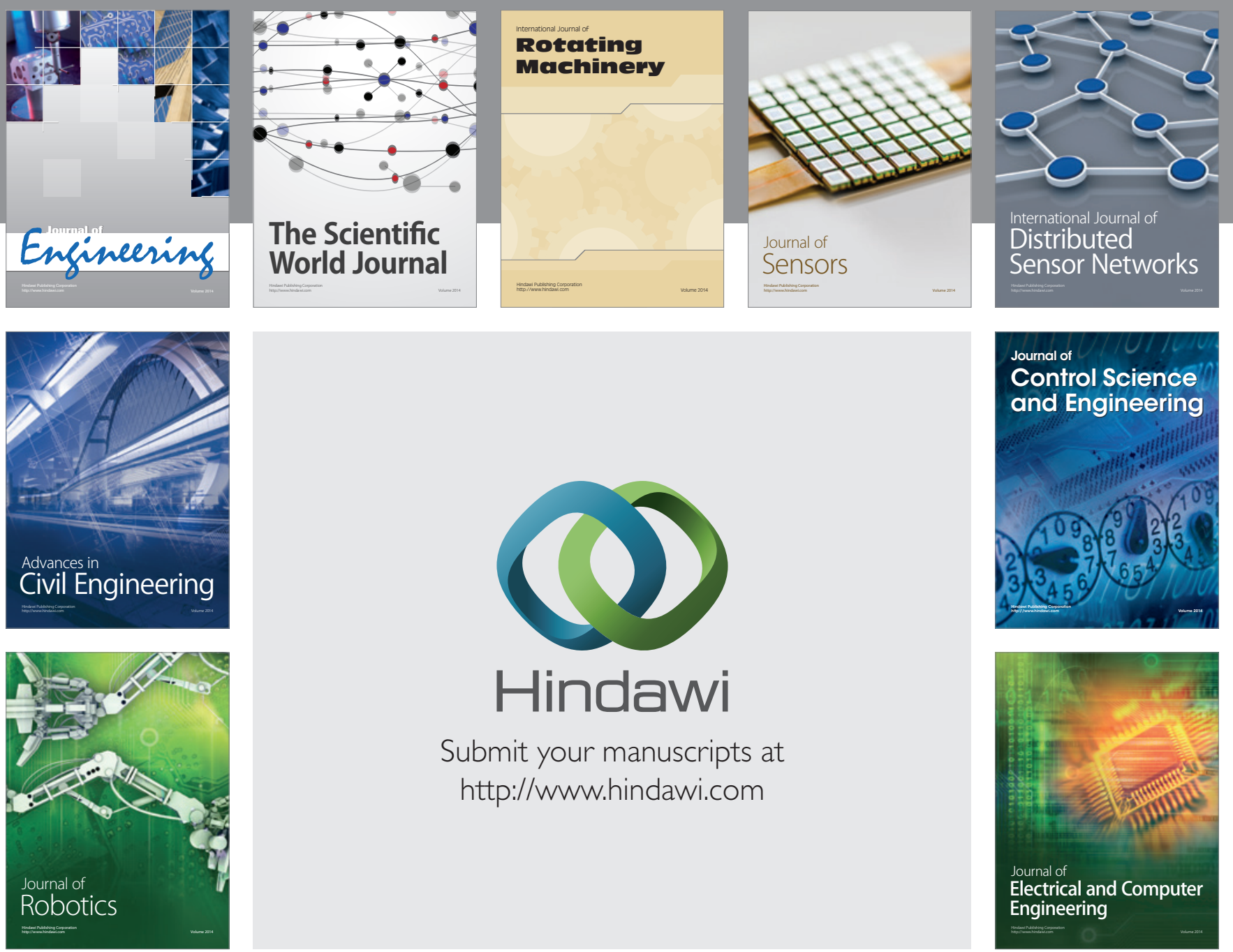

Submit your manuscripts at

http://www.hindawi.com
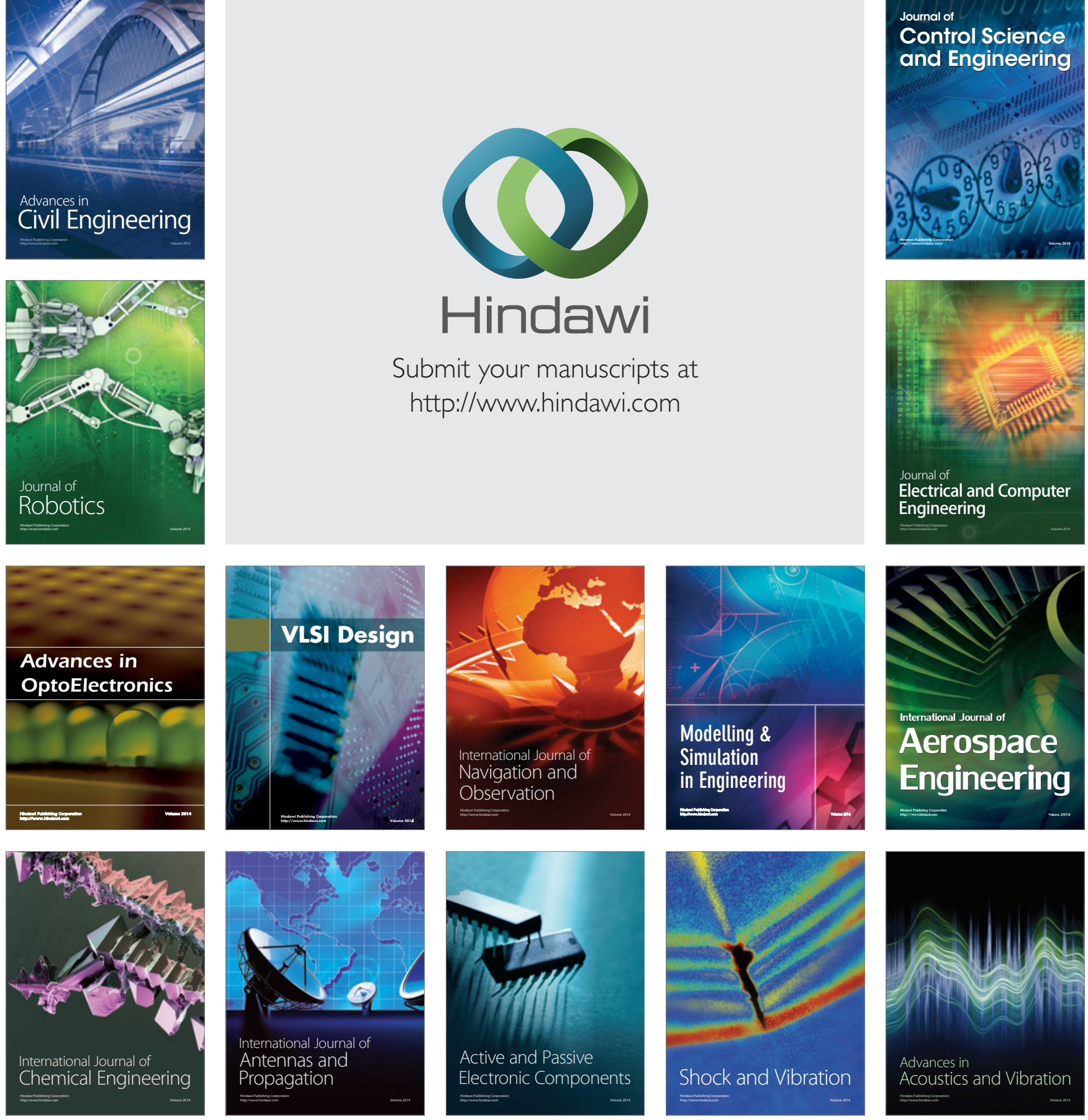